\title{
Short-circuit fault diagnosis of the DC-Link capacitor and its impact on an electrical drive system
}

\author{
Mohamed Amine Khelif, Azeddine Bendiabdellah, Bilal Djamal Eddine Cherif \\ Diagnostic Group, LDEE Laboratory, Department of Electrical Engineering, Faculty of Electrical Engineering, \\ University of Science and Technology of Oran MB, Algeria
}

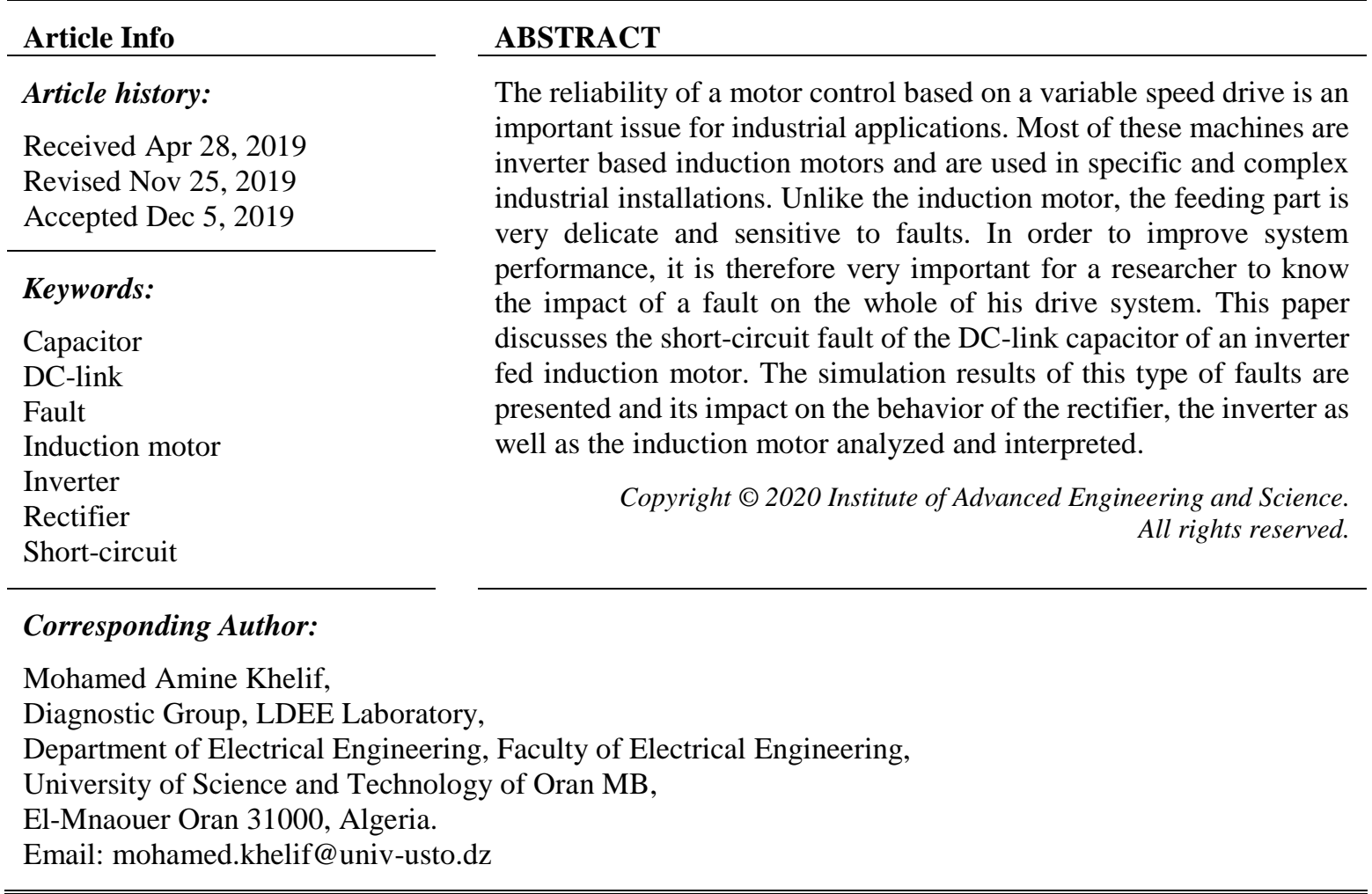

\section{INTRODUCTION}

Modern electrical drive systems are very dependent on the control of induction motors. The pulse width modulation (PWM) techniques is one of the most known control techniques [1]. Thanks to the evolution of power electronics, the control mechanism of these motors has become simple and economical for performances similar to those of DC motors. However, the frequent use of induction motors in the automation process has also raised questions about their performance under fault conditions at different levels. Motors can be a part of basics drive systems [2,3] or more complex ones such as wind energy conversion systems [4]. They can be supplied by conventional inverters or matrix inverters [5].

Induction motor fault analysis is an important research focus for improving the reliability of variable speed drive systems. Several researchers $[6,7]$, have mobilized their knowledge and skills and orientate their works on this research field. Diffrents types of faults have been studied, and some motor models are developed and dedicated for these faults' types. For example, bearing fault [8], open phase fault [9], broken bar fault [10], short-between turns fault, etc. These motors are known for their simplicity of construction, use and maintenance, its robustness and its low cost price. In most industrial applications, induction motors are variable speed based. They are powered by a combination of a rectifier, a DC-Link and an inverter; which requires a lot of attention to study the behavior of the motor in the presence of a fault in their supply system. These faults mainly concern IGBT's faults, control circuits or DC-link capacitor faults. These elements are the main components that constitute a variable speed system and wind energy conversion systems $[11,12,4]$. The induction motors performances in the presence of power electronics and semiconductor related faults are 
well presented in the literature $[13,14]$. The faults probability mentioned above is already calculated taking into account several factors; a detailed study is presented in the following papers [12, 14]. The Reliability Evaluation of Wind Turbine Systems' Components shows that the higher failure rate is at the level of the converters; which one the DC link is a part [15].

According to some researchers, the reliability of semiconductors has increased considerably. It perseveres with the fact that in the past, the possibility of control circuit's faults was $53.1 \%$ and it was only due to the less reliability and less sophistication of PWM chips compared to what we can have as modern controller technology today. Thus the risk of IGBT's faults is reduced. Since that, capacitors have been used in a large number of power electronics applications, including inverters and switching power supplies [12]. A research study [14] concluded that more than half of the faults in switching power supplies are related to the DC-Link capacitor faults. On the basis of this work's theory [14], a new research that has been developed on [12] deduces that the same hypothesis can also be applied to the DC-link capacitor of an inverter. This study also demonstrated that the estimated possibility of capacitor faults for different circuits is about $60 \%$ [12]. It further emphasized that the capacitor faults rates are high, that makes it very important for research work and should be taken into account for variable speed drives faults analysis.

In [16], a review on the DC-link capacitor reliability improvement in power electronic static converters is presented. Fault modes, their reasons, and capacitor lifetime models are clarified and summarized to understand the physics of failure and improve DC-link design. This paper highlights the importance of the DC-link monitoring. The DC-link short-circuit fault is materialized by a capacitor short-circuit. This kind of fault can mainly be caused by breaks in connectors [16]. The results show that the capacitor is vulnerable to defects. It is worth mentioning that the equivalent series resistance (ESR) of the capacitor increases with time. In ordinary circuits, the problem does not arise, however when the capacitor is part of a switching circuit, the equivalent series resistance can combine with the switching frequency and possibly lead to self-heating; which can indirectly cause capacitor fault.

On this fact, another paper proposes a DC-link condition monitoring method for two-level AC/DC/AC converters. This method is based on the DC-link voltage measurement and DC-link current reconstruction. An online evaluation of the equivalent series resistance (ESR) of the DC-link capacitor is done and the ESR increase is used as a fault indicator [17]. Many researchers have studied faults in drive systems. However, they focused on the diagnosis of IGBT's switches faults [18, 19]. Most researches have cited the problem of DC-link capacitor faults in their work but have not systematically studied it extensively [11, 20]. Other researchers [21] have commented on the voltage drop in the DC-link, but only for a transient moment.

In general, some researches were done on the DC-link short-circuit fault and its impact on the induction motor [22-24]. Recently, a study has presented a review of internal and external defects at different parts of a motor associated with an inverter [25]. However all this researches did not deal with its impact on the three-phase rectifier. This bibliographical synthesis reveals that most of the works in the field of fault analysis of induction motors variable speed based are related to the IGBT's switches fault analysis. However, the capacitor vulnerability prompts us to perform a thorough analysis of the behavior of the rectifier, the inverter and the induction motor in the presence of this type of fault.

In this paper work, an induction motor variable speed based is considered. A synthesis of a mathematical analysis of the short-circuit fault of the DC-link capacitor is presented. A simulation of the behavior of this drive system under this type of fault was developed to support the synthesis of the mathematical analysis. Its signature is studied and its impacts on the whole drive system (the rectifier, the inverter and the induction motor) are presented. The obtained results can help the researchers to design and improve a fault-tolerant system as well as an optimal protection system design.

\section{DC-LINK CAPACITOR SHORT-CIRCUIT FAULT ANALYSIS}

This research highlights that DC-link short-circuit capacitor fault can damage the rectifier if the protection fuses are not well suited, and also stop the operation of the inverter and the induction motor immediately. Figure 1 shows a simplified representation of an electrical drive system and how to simulate a DC-link capacitor short-circuit fault. The studied electrical drive system is constructed of a combination of a rectifier, an inverter and an induction motor. The fault is simulated by the paralleling of an ideal switch $\mathrm{K}$ with the DC-link capacitor which will be closed at the moment of the fault application $\mathrm{t}=2 \mathrm{~s}$. Note that the sampling frequency is $F_{s}=200 \mathrm{kHz}$. As shown in Figure 1, the DC-link capacitor short-circuit fault causes on both sides a short-circuit sharing a common branch of the DC-link; rectifier and power line side, inverter and induction motor side. In this part a global mathematical analysis for both cases has been synthesized.

Figure 2 shows an equivalent electrical circuit of a combination of a rectifier, an inverter and an induction motor for a variable speed application. The three-phase voltages coming from the electrical network $\mathrm{V}_{\mathrm{a}}, \mathrm{V}_{\mathrm{b}}$, and $\mathrm{V}_{\mathrm{c}}$ are converted into DC voltage $\mathrm{Vdc}$ using a controlled three-phase rectifier. The DC voltage 
obtained is supplied to the DC-link and filtered using a capacitor C. The rectifier and the inverter outputs voltages are generated by the pulse width modulation (PWM) technique. The inverter output currents have a sinusoidal waveform. The stator currents of the induction motor are generally sinusoidal waveform.

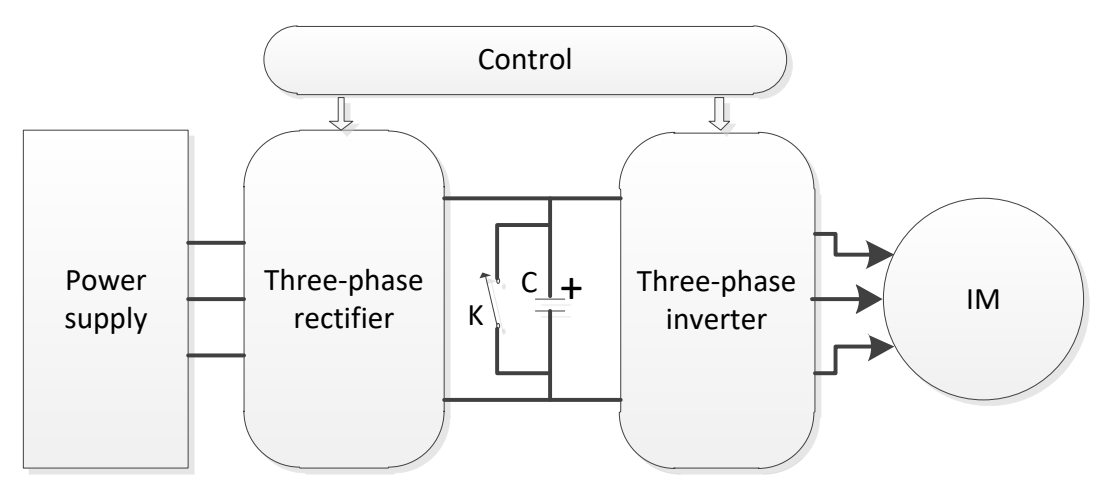

Figure 1. Representation of a DC-link capacitor short-circuit fault at the level of an electrical drive system

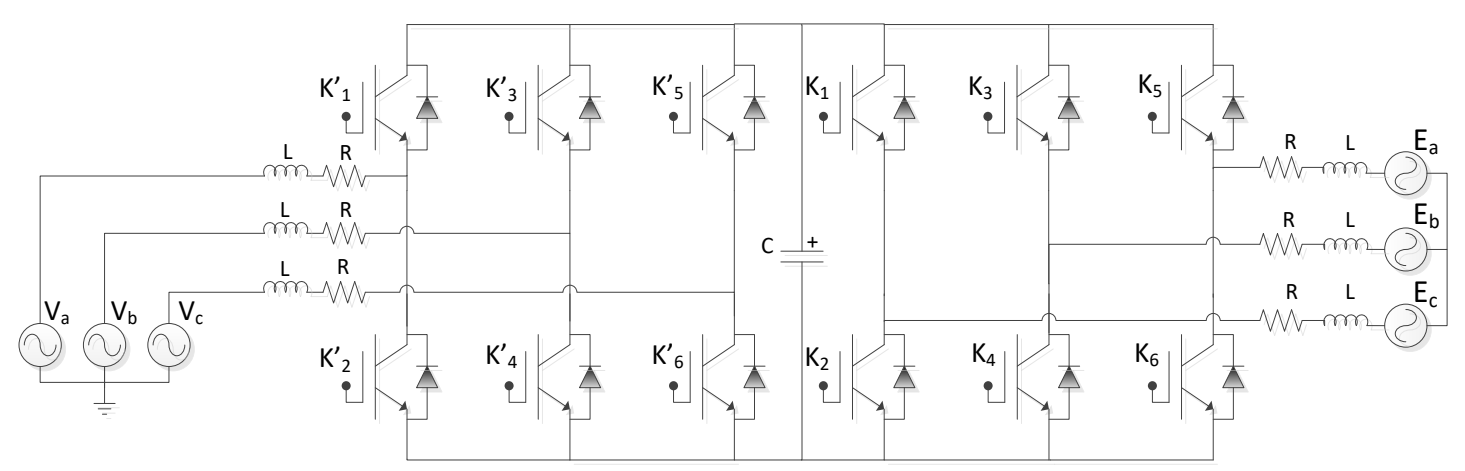

Figure 2. Equivalent electrical circuit of a combination of a rectifier, an inverter and an induction motor

\subsection{Electrical network and the rectifier side fault analysis}

This fault short-circuits the rectifier output voltage and consequently short-circuits the electrical network phases. To explain the phenomenon in a clear manner, we consider Figure 3. It is a simple circuit to represent the problem [22]. Suppose we are focused on the rectifier side and electrical network. The switch K is connected in parallel with the filter capacitor. The DC voltage source applies a DC voltage responsible for the charge of the capacitor. Vdc is a simplified representation of the output of the three-phase rectifier used in the simulation configuration of the electrical drive system. The resistor $\mathrm{R}$ is not shown since the short-circuit path contains a very low resistance.

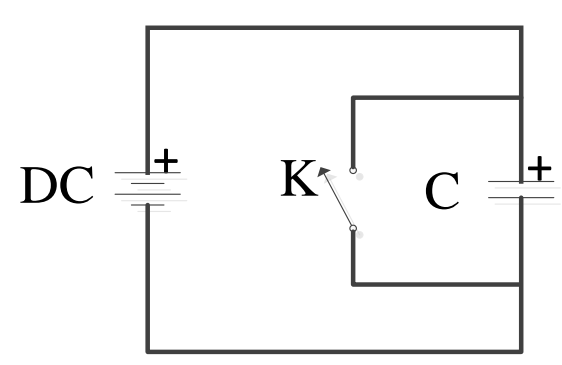

Figure 3. Simplified scheme of an equivalent circuit of a capacitor short-circuit fault 
At the moment $(\mathrm{t}=0-)$, before closing the switch $\mathrm{K}$, the voltage across the capacitor is:

$$
V_{(t=0-)}=V_{d c}
$$

that is, the filter capacitor voltage is equal to rectifier output DC voltage. Therefore, when the capacitor voltage is equal to $\mathrm{Vdc}$, the current is zero.

$$
i_{c(t=0-)}=0
$$

The presence of a single capacitor in the variable speed system construction at the DC-link level means that there is no other device to limit and stop the abrupt change in current. Therefore, at $(\mathrm{t}=0)$, when the switch $\mathrm{K}$ is closed, the capacitor is short-circuited. Knowing that the resistance is almost zero. The source current increases exponentially.

$$
i_{c(t=0-)}=V / R
$$

Since R tends to zero, (3) becomes:

$$
i_{c(t=0-)}=\infty
$$

the circuit condition after the switch $\mathrm{K}$ is closed is the same as for an $\mathrm{RC}$ circuit, then:

$$
i=k e^{\left(-\frac{t}{R C}\right)}
$$

After closing the switch $\mathrm{K}$, the resistance $\mathrm{R}$ becomes almost zero; that is, if $\mathrm{R}=0$, the circuit generates a very strong current that tends to infinity. As a result, this fault can cause serious problems. It may damage the rectifier if the selected fuses are not properly rated.

\subsection{Inverter and induction motor side fault analysis}

Let's see the inverter and induction motor side. The electromotive force (EMF) is presented as a sinusoidal variable voltage source, and the motor winding parameters are represented as a series resistance and inductance for each of the three phases. The IGBT's function as switches so that they establish or break the DC-link connection with the induction motor; as shown in Figure 2 For example, consider a state where IGBTs $\mathrm{K}_{1}, \mathrm{~K}_{4}$, and $\mathrm{K}_{6}$ are Passing (close) and IGBTs $\mathrm{K}_{2}, \mathrm{~K}_{3}$, and $\mathrm{K}_{5}$ are non-passing (open). Figure 4 shows a simplified circuit representing the fault on the inverter and the induction motor side [23].

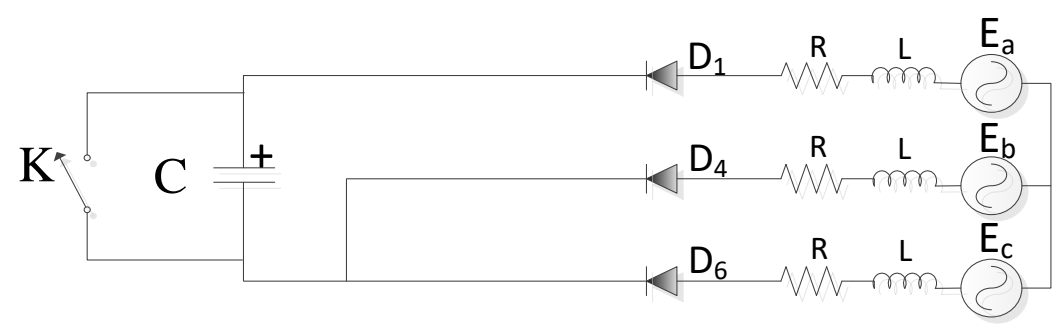

Figure 4. Fault equivalent circuit on the inverter and the induction motor side under DC-link short capacitor short-circuit fault

At this time, the phase-A current is equal to the sum of the currents of the phase-B and the phase-C as indicated in (6):

$$
I_{a}=I_{b}+I_{c}
$$

The current flows from phase-A which is connected to the positive terminal of the DC-link. The voltage equation for the phase is given in (7): 


$$
V_{a 0}=V_{z}+E_{b a}
$$

where: $\mathrm{V}_{\mathrm{ao}}$ is phase-A voltage relative to ground, $\mathrm{V}_{\mathrm{z}}$ is the line impedance voltage drop, $\mathrm{E}_{\mathrm{ba}}$ is the induction motor EMF return for phase-A. So (7) becomes:

$$
V_{a o}=R \cdot i+L(d i / d t)+E_{b a}
$$

after the DC-link capacitor short-circuit fault, the inverter output voltage becomes zero as indicated in [25]. As a result, (8) becomes:

$$
-E_{b a}=R \cdot i+L(d i / d t)
$$

at the moment $(\mathrm{t}=0-)$, the current expression is given by:

$$
i_{r(t=0-)}=i_{l(t=0-)}=\left(E_{b a}-V_{d c}\right) / R
$$

at the moment $(\mathrm{t}=0)$, the switch $\mathrm{K}$ is closed, thus creating a short circuit along DC voltage source. As a result, the voltage Vdc becomes zero. The the induction motor electromotive forces begin to fall over time. So (10) becomes:

$$
i_{r(t=0)}=i_{l(t=0)}=E_{b a} / R
$$

as there is an inductance $\mathrm{L}$ in the mesh, it will oppose the current sudden, so it cannot change instantaneously. However, the current will follow the particular solution given below in (12).

$$
i=\left(E_{b a} / R\right) /\left(1-e^{-\frac{t}{\tau}}\right)
$$

The transient short-circuit current decreases indefinitely due to the winding resistor $\mathrm{R}$ presence. The time constant $\tau$ defines the time necessary to eliminate the stator current transient effects. During the steady state, the voltage applied to the motor becomes zero, which causes an immediate shutdown of the induction motor operation.

\section{SIMULATION RESULTS AND INTERPRETATION}

$T$ In this simulation, the induction motor is loaded at time $t=1 \mathrm{~s}$ with a load torque $C_{l}=20$ N.m. The fault is simulated by closing the switch $\mathrm{K}$ at $\mathrm{t}=2 \mathrm{~s}$. It can be seen in Figure 5 that the DC-link voltage Vdc is maintained stable over its rated value in the healthy state. At the moment of the fault application, the voltage becomes almost zero. In Figure 6 a significant increases in three-phase currents on the rectifier and the electrical network side are noted. It can be seen in Figure 7 and Figure 8 that the inverter output voltages and the induction motor absorbed current fall to zero just after the fault is happen. Figure 9 shows the induction motor stator three-phase currents. Appearances of considerable transient currents are noted at the time of the fault application, and then they decrease to reach a zero value.

Figure 10 shows that the induction motor was running at its nominal speed before the fault application. At the moment of the fault appearance, the speed gradually decreases until it becomes zero; that is, the induction motor starts to slow down slowly until it stops. It is observed in Figure 11 that when there is no applied load, the electromagnetic torque is zero. When the induction motor is loaded, it increases and reaches that load torque rated value. As soon as the fault appears, the electromagnetic torque immediately takes a very large negative value before becoming zero. DC-link capacitor fault can be a serious problem if the motor is running at high speed and has high inertia. Greater will be the inertia, longer will be the electromotive force return generation time. These electromotive forces decrease and cancel with the inverter output voltages creating large amplitude transient currents. On the rectifier and the electrical network side the short circuit makes the currents rise at very large amplitudes and consequently, the deterioration risks of the converter electronic power components are very present. The simulation results of our electrical drive system are given as shown in Figures 5-11. 


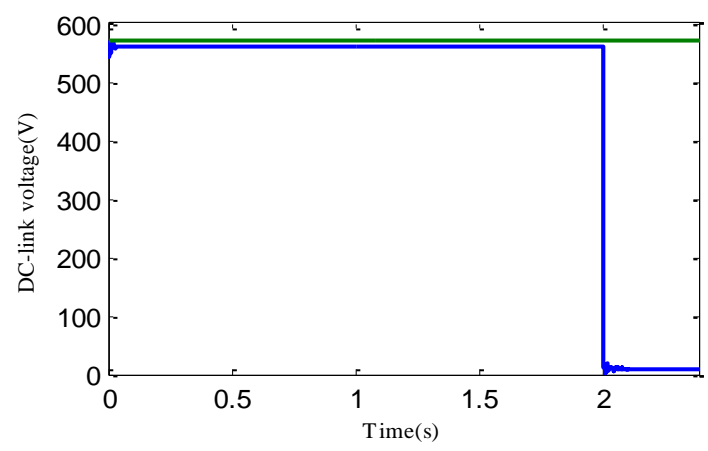

Figure 5. DC-link-voltage

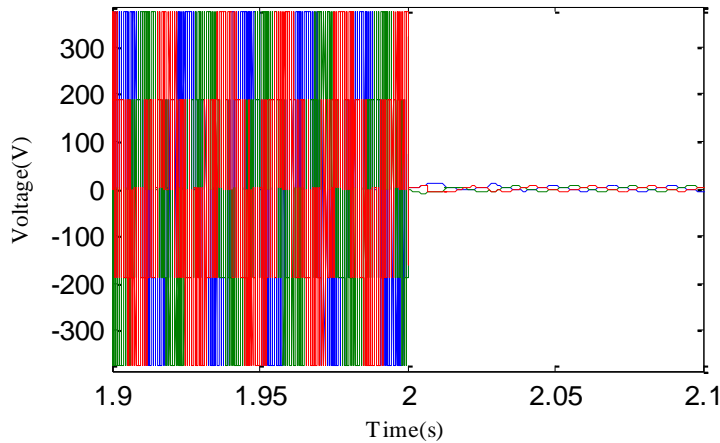

Figure 7. Inverter output three-phase voltages

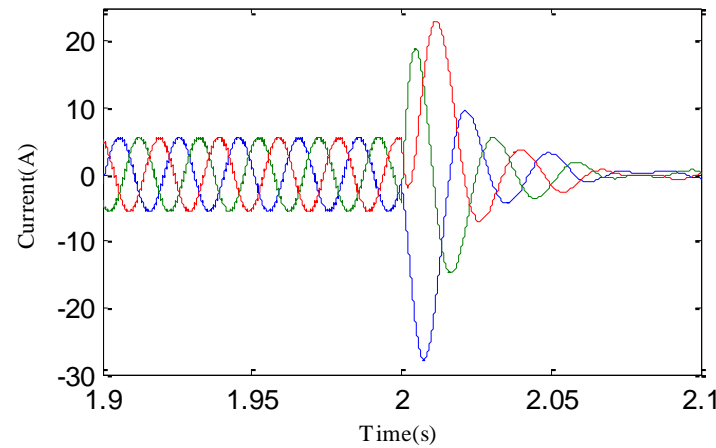

Figure 9. Induction motor stator three-phase currents

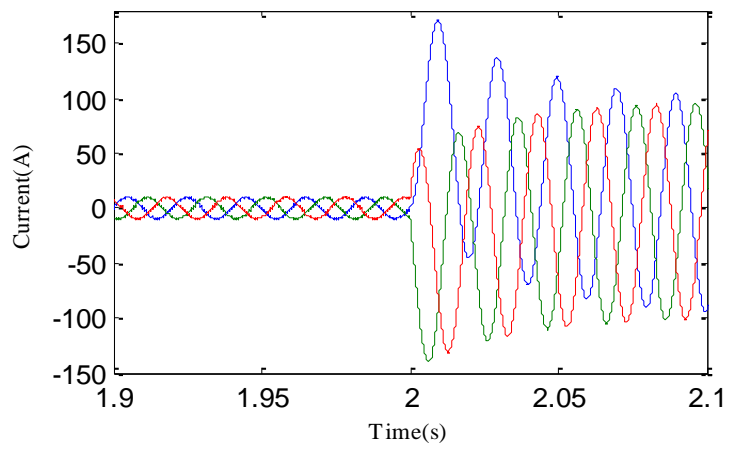

Figure 6. Rectifier three-phase currents on the electrical network side

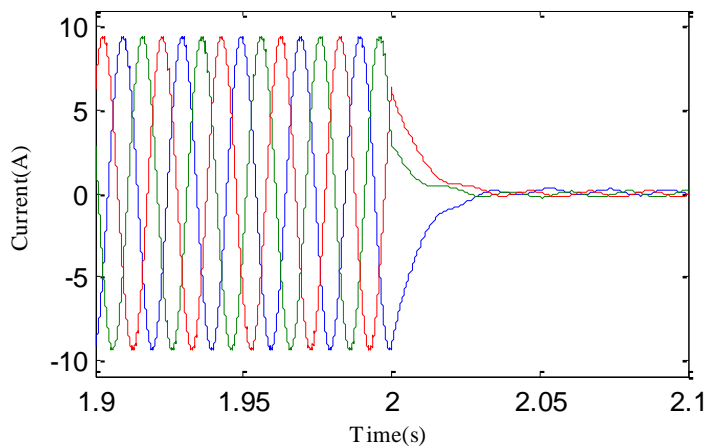

Figure 8. Inverter output three-phase currents

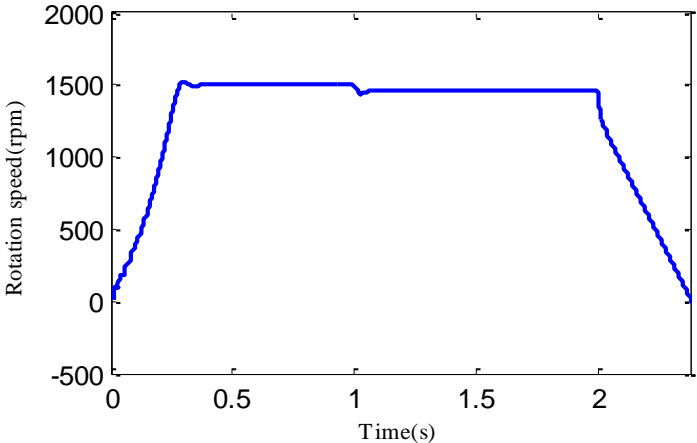

Figure 10. Induction motor Rotation speed

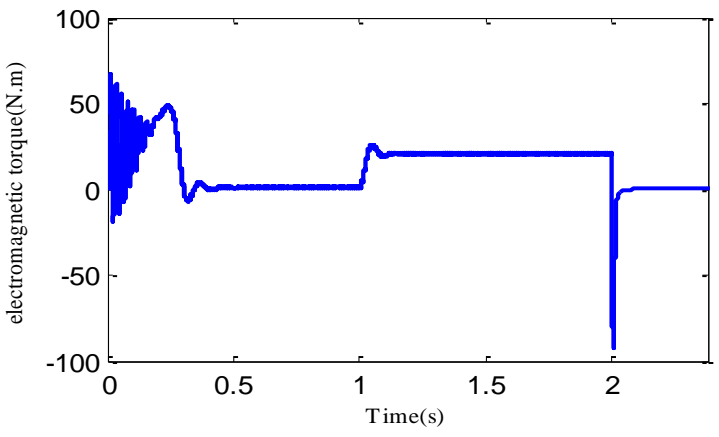

Figure 11. Electromagnetic torque 


\section{CONCLUSION}

This article mainly highlights the impact of the DC-link capacitor short-circuit fault on the electrical and mechanical behavior of an entire electrical drive system; composed of an induction motor powered by a variable speed system (a rectifier, a DC-link and an inverter). The theory and the mathematical analysis given are verified by simulations. This study allowed us to gather information on the behavior of the rectifier, the inverter and the induction motor during a Dc-link capacitor short-circuit fault. Detailed analysis certainly contributes to the diagnosis and design of good fault-tolerant systems as well as improving fault detection techniques.

\section{REFERENCES}

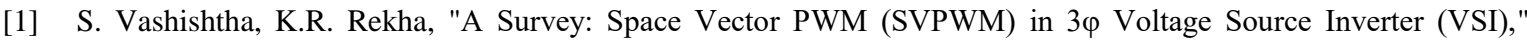
International Journal of Electrical and Computer Engineering (IJECE), vol. 8, no. 1, pp. 11-18, 2018.

[2] A. Ramesh, O. Chandra Sekhar, M. Siva Kumar, "A Novel Three Phase Multilevel Inverter with Single DC Link for Induction Motor Drive Applications," International Journal of Electrical and Computer Engineering (IJECE), vol. 8, no. 2, pp. 763-770, 2018.

[3] A. Suresh Kumar, R.K. Pongiannan, C. Bharatiraja, Adedayo Yusuf, N. Yadaiah, "Non isolated coupled converter tied voltage source inverter Drive," International Journal of Power Electronics and Drive System (IJPEDS), vol. 10, no. 2, pp. 645-652, 2019.

[4] A. M. Shiddiq Yunus, Makmur Saini, Ahmed Abu-Siada, "Dynamic performance comparison of DFIG and FCWECS during grid faults," TELKOMNIKA (Telecommunication, Computing, Electronics and Control), vol. 17, no. 2, pp. 1040-1046, 2019.

[5] A.C. Subrata, T. Sutikno, A.Z. Jidin, "Review on Adjustable Speed Drive Techniques of Matrix Converter Fed Three-Phase Induction Machine," in of the 5th International Conference on Electrical Engineering, Computer Science and Informatics (EECSI 2018), 2018.

[6] M. Riera-Guasp, J. A. Antonino-Daviu, G. A. Capolino, "Advances in electrical machine, power electronic and drive condition monitoring and fault detection: State of the art", IEEE Transactions on Industrial Electronics, vol. 62, no. 3, pp. 1746-1759, 2015.

[7] Y. Liu and A. M. Bazzi, "A review and comparison of fault detection and diagnosis methods for squirrel-cage induction motors: State of the art," ISA Transactions, vol. 70, pp. 400-409, 2017.

[8] M. Hadjami, H. Razik, M. E. K. Oumaamar, A. Kezzar, "Analytical Model of Cage Induction Machine Dedicated to the Study of the Inner Race Bearing Fault," International Journal of Electrical and Computer Engineering (IJECE), vol. 8, no. 1, pp. 458-471, 2018.

[9] M. Atig, M. Bouheraoua, A. Fekik, "An Experimental Investigation of Heating in Induction Motor under Open Phase Fault," International Journal of Electrical and Computer Engineering (IJECE), vol. 8, no. 3, pp. 1288-1296, 2018.

[10] S. Lachtar, A. Ghoggal, K. Koussa, A. Bouraiou, I. Attoui, "Broken rotor bar fault diagnostic for DTC fed induction motor using stator instantaneous complex apparent power envelope signature analysis," International Journal of Power Electronics and Drive System (IJPEDS), vol. 10, no. 3, pp. 1187-1196, 2019.

[11] D. Kastha, B. K. Bose, "Investigation of fault modes of voltage-fed inverter system for induction motor drive," IEEE Trans. Indust. Appl, vol. 30, no. 4, pp. 1028-1038, 1994.

[12] F. W. Fuchs, "Some diagnosis methods for voltage source inverters in variable speed drives with induction machines-a survey," in IECON'03. 29th Annual Conference of the IEEE Industrial Electronics Society, 2004.

[13] B. Biswas, S. Das, P. Purkait, M. S. Mandal and D. Mitra, A.J.M. Cardoso, "Current harmonics analysis of inverterfed induction motor drive system under fault conditions," Diagnostics for electric machines, power electronics and drives, Proceedings of the International MultiConference of Engineers and Computer Scientists 2009, IMECS 2009, vol. 2, March 2009.

[14] A. Lahyani, P. Venet, G. Grellet, P.-J. Viverge, "Failure prediction of electrolytic capacitors during operation of a switchmode power supply," Power Electron., IEEE Trans., vol. 13, no. 6, pp. 1199-1207, 1998

[15] Seyed Mohsen Miryousefi Aval, Amir Ahadi, "Reliability Evaluation of Wind Turbine Systems' Components," Bulletin of Electrical Engineering and Informatics, vol. 5, no. 2, pp. 160-168, 2016.

[16] H. Wang and F. Blaabjerg, "Reliability of capacitors for DC-link applications in power electronic converters-An overview," IEEE Trans. Ind.Appl, vol. 50, no. 5, pp. 3569-3578, 2014.

[17] P. Lipnicki, D. Lewandowski, "DC-Link Condition Monitoring Method for Two-Level Ac/Dc/Ac Converters, Power Electronics and Drives, vol. 2, no. 1, pp. 40-56, 2017.

[18] B. D. E. Cherif, A. Bendiabdellah, M. Bendjebbar A. Telli, "A comparative study between methods of detection and localisation of open-circuit faults in a three-phase voltage inverter fed induction motor," International Journal of Modelling, Identification and Control (IJMIC), vol. 29, no. 4, pp. 327-340, 2018.

[19] Cherif, B. D. E., Bendiabdellah, A., Khelif, M. A., "Detection of Open-Circuit Fault in a Three-Phase Voltage Inverter Fed Induction Motor", International Review of Automatic Control (IREACO), vol. 9, no. 6, pp. 374-382, 2016.

[20] R.L.A. Ribeiro, C.B. Jacobina, E.R.C. Da Silva, A.M.N. Lima, "Fault detection in voltage-fed PWM motor drive systems," in Power Electronics Specialists Conference, 2000. PESC 00. 2000 IEEE 31st Annual, vol. 1, pp. 242-247, 2000. 
[21] E. Ebrahim and N. Hammad, "Fault analysis of current-controlled pwm-inverter fed induction-motor drives," in Proceedings of the $7^{\text {th }}$ International Conference on Properties and Applications of Dielectric Materials, vol. 3, pp. 1065-1070, 2003.

[22] H.A. Sher, Z.J. Paracha, Y. Khan, and K.E., Addoweesh, "Fault analysis of an inverter fed induction motor under DC link capacitor short circuit condition," Proceedings of 5th Global Conference on Power Control and Optimization, 2011.

[23] H. A. Sher, K. E. Addoweesh, Y. Khan, "Effect of short-circuited dc link capacitor of an ac-dc-ac inverter on the performance of induction motor," Journal of King Saud University, vol. 28, no. 2, pp. 1-8, 2014.

[24] H.A. Sher, K.E. Addowesh, Z. Khalid, Y. Khan, "Theoretical and experimental analysis of inverter fed induction motor system under DC link capacitor failure," J. King Saud Univ. Eng. Sci, vol. 29, no. 2, pp. 103-111, 2017.

[25] B. D. E. Cherif, A. Bendiabdellah, M. Bendjebbar, N. Benouzza, M. A. Khelif, "Review on external and internal faults of an association inverter-motor and their impact on the motor operation," Green Energy Conversion Systems (GECS), 2017 International Conference, 2017.

\section{APPENDIX}

All the parameters of the used induction motor are presented the following Table 1.

Table 1. Parameters of the used induction motor

\begin{tabular}{lc}
\hline Power supply & $380 \mathrm{~V}$ \\
\hline Coupling & $\Delta$ \\
Rated power & $3 \mathrm{~kW}$ \\
Nominal current & $7 \mathrm{~A}$ \\
Rated speed & $1440 \mathrm{tr} / \mathrm{min}$ \\
Stator resistance & $6 \Omega$ \\
Rotor resistance & $2.8 \Omega$ \\
Stator cyclic inductance & $0.5668 \Omega$ \\
Rotor cyclic inductance & $0.5142 \Omega$ \\
Mutual inductance & $0.5142 \Omega$ \\
poles pairs number & 2 \\
Moment of inertia & $0.058 \mathrm{~kg} . \mathrm{m} 2$ \\
Load torque & $20 \mathrm{~N} . \mathrm{m}$ \\
Coefficient of viscous friction & $0.005 \mathrm{~N} . \mathrm{m} . \mathrm{rad}-1 . \mathrm{s}$ \\
\hline
\end{tabular}

\section{BIOGRAPHIES OF AUTHORS}

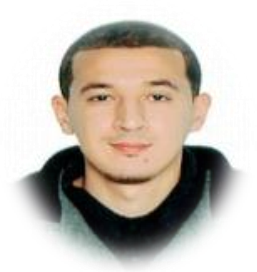

Mohamed-Amine Khelif was born in Miliana, Ain-Defla, Algeria, in 1991. He received his bachelor and Master degrees from the University Djilali Bounaama, Algeria in 2013 and 2015 respectively. He is currently working for his Ph.D degree at USTO-MB, Algeria. His research interests include: Power Conversion and Electric Machines and Drives and Tolerance.

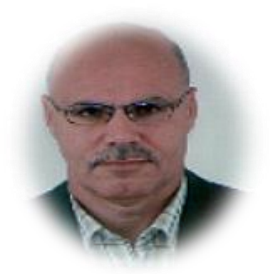

Azeddine Bendiabdellah, IEEE Member, Algeria. He received his Bachelor Engineering degree with honors and his Ph.D degree from the University of Sheffield, England, in 1980, and 1985 respectively. From 1990 to 1991 he was a visiting professor at Tokyo Institute of Technology (T.I.T), Japan. He is currently Professor lecturer and researcher in Electrical Engineering Faculty at the University of Sciences and Technology of Oran, (USTO-MB) Algeria. His research interests include: Electrical machines and Drives Modelling and Analysis, Electrical machines and Drives Control and Converters as well as Electrical machines and drives Faults Diagnosis and Tolerance.

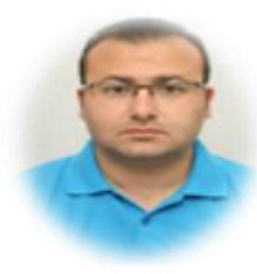

Bilal-Djamal-Eddine Cherif, IEEE student Member, was born in Algeria, in 1984. $\mathrm{He}$ received his Engineering degree from the University of M'sila, Algeria in 2010 and his Magister Degree in Electrical Engineering from the University of Sciences and Technology of Oran (USTO-MB), Algeria in 2015 respectively. He is Ph.D degree at USTO-MB, Algeria. His research interests include: Power Conversion and Electric Machines and Drives and Tolerance. 